\title{
Review Article \\ The Role of Dopamine and Its Dysfunction as a Consequence of Oxidative Stress
}

\author{
Hugo Juárez Olguín, ${ }^{1,2}$ David Calderón Guzmán, ${ }^{3}$ \\ Ernestina Hernández García, ${ }^{1}$ and Gerardo Barragán Mejía ${ }^{3}$ \\ ${ }^{1}$ Laboratorio de Farmacología, Instituto Nacional de Pediatría (INP), 04530 Ciudad de México, DF, Mexico \\ ${ }^{2}$ Departamento de Farmacología, Facultad de Medicina, Universidad Nacional Autónoma de Mexico, \\ 04130 Ciudad de México, DF, Mexico \\ ${ }^{3}$ Laboratorio de Neuroquimica, INP, 04530 Ciudad de México, DF, Mexico
}

Correspondence should be addressed to Hugo Juárez Olguín; juarezol@yahoo.com

Received 10 June 2015; Revised 21 July 2015; Accepted 26 August 2015

Academic Editor: Anne-Laure Bulteau

Copyright ( 2016 Hugo Juárez Olguín et al. This is an open access article distributed under the Creative Commons Attribution License, which permits unrestricted use, distribution, and reproduction in any medium, provided the original work is properly cited.

\begin{abstract}
Dopamine is a neurotransmitter that is produced in the substantia nigra, ventral tegmental area, and hypothalamus of the brain. Dysfunction of the dopamine system has been implicated in different nervous system diseases. The level of dopamine transmission increases in response to any type of reward and by a large number of strongly additive drugs. The role of dopamine dysfunction as a consequence of oxidative stress is involved in health and disease. Introduce new potential targets for the development of therapeutic interventions based on antioxidant compounds. The present review focuses on the therapeutic potential of antioxidant compounds as a coadjuvant treatment to conventional neurological disorders is discussed.
\end{abstract}

\section{Introduction to Dopamine}

Dopamine (DA) plays a vital role in reward and movement regulation in the brain. In the reward pathway, the production of DA takes place in the ventral tegmental area (VTA), in nerve cell bodies. From there, it is released into the nucleus accumbens and prefrontal cortex. In vivo, the concentration of DA in the VTA is $4.8 \pm 1.5 \mathrm{nM}$, while in red nucleus, it is $0.5 \pm 1.5 \mathrm{nM}$ [1]. The pathway for motor functions is different. In this pathway, the substantia nigra cell bodies are responsible for the production and discharge of DA into the striatum. DA plays multiple functions in the brain. Calabresi et al. reported the role of DA in the modulation of behavior and cognition; voluntary movement; motivation; punishment and reward; inhibition of prolactin production; sleep; dreaming; mood; attention; working memory; and learning [2].

DA can be a precursor in the biosynthesis of other related catecholamines such as norepinephrine and epinephrine (Figure 1). Norepinephrine is synthesized from DA by the catalytic action of DA $\beta$-hydroxylase in the presence of $\mathrm{L}$ ascorbic acid and molecular oxygen $\left(\mathrm{O}_{2}\right)$. Norepinephrine then acted upon by the enzyme phenylethanolamine $\mathrm{N}$ methyltransferase with $S$-adenosyl-L-methionine (SAMe) as a cofactor to produce epinephrine.

The biosynthesis of DA and other catecholamines can be limited by the action of enzyme tyrosine hydroxylase (TH) [3]; therefore, regulatory mechanisms of TH could be promising for improving gene therapy approaches and other treatment modalities [4]. After the synthesis of DA, it is incorporated into synaptic vesicles by the action of vesicular monoamine transporter $2\left(\mathrm{VMAT}_{2}\right)$, where it is stored. $\mathrm{DA}$ is discharged by exocytosis into the cell membrane and dumped into the synapse.

\section{Dopamine Receptors}

In the synapse, DA binds to either postsynaptic or presynaptic DA receptors or both. This bond, regardless of the receptor, generates an electric potential in the presynaptic cell [5]. 


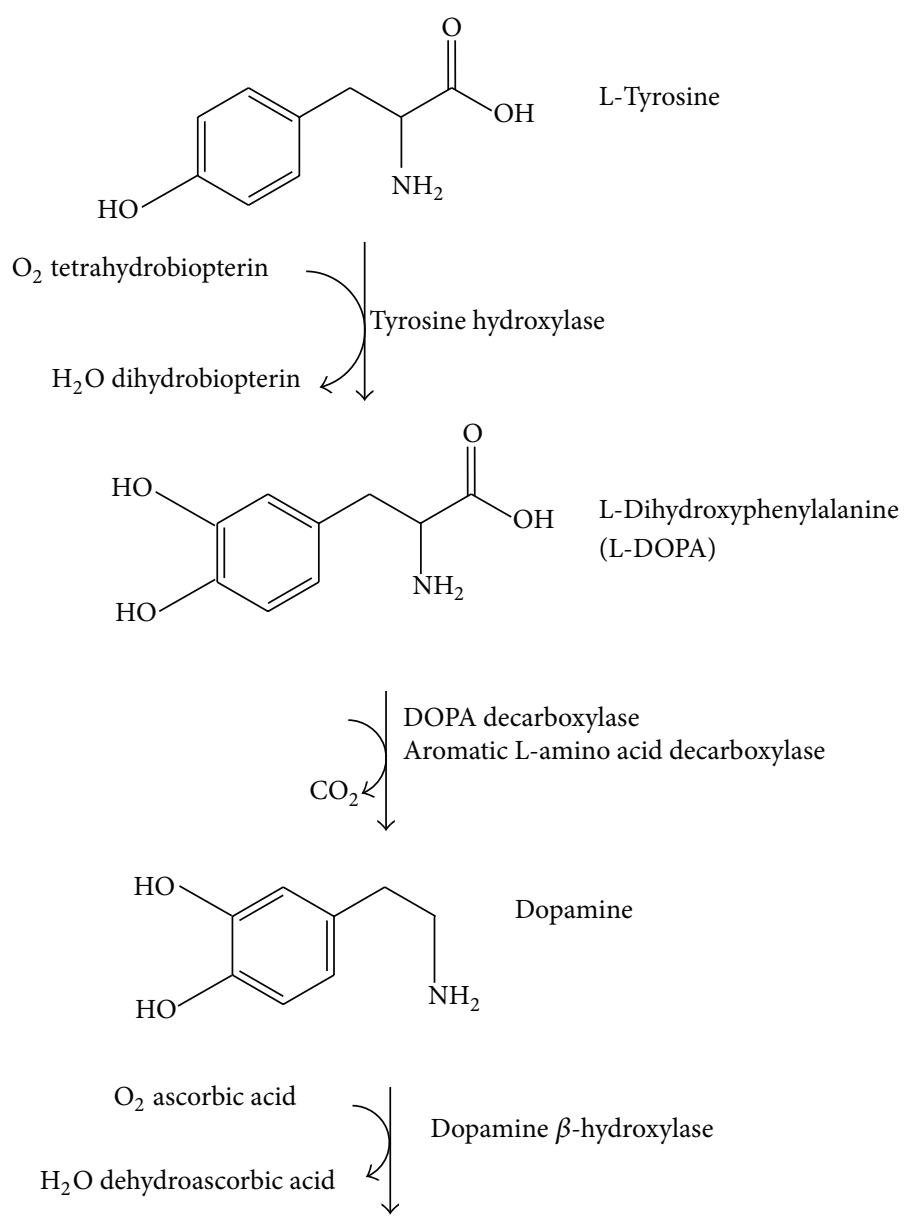<smiles>CCCCCCCCCCN</smiles>

Shenylethanolamine
N-Methyltransferase<smiles>CNCC(O)c1ccc(O)c(O)c1</smiles>

FIGURE 1: Catecholamine biosynthesis.

In the case of postsynaptic DA receptors, the signal is propagated to the postsynaptic neuron, while, in the case of presynaptic DA receptors, the signal can either excite the presynaptic cell or inhibit it. Presynaptic receptors with an inhibitory potential, also known as autoreceptors, inhibit the synthesis and release of neurotransmitters and thus function to maintain normal levels of DA. After carrying out its synaptic function, DA is taken up again into the cytosol by presynaptic cells through the actions of either high-affinity DA transporters (DAT) or low-affinity plasma 


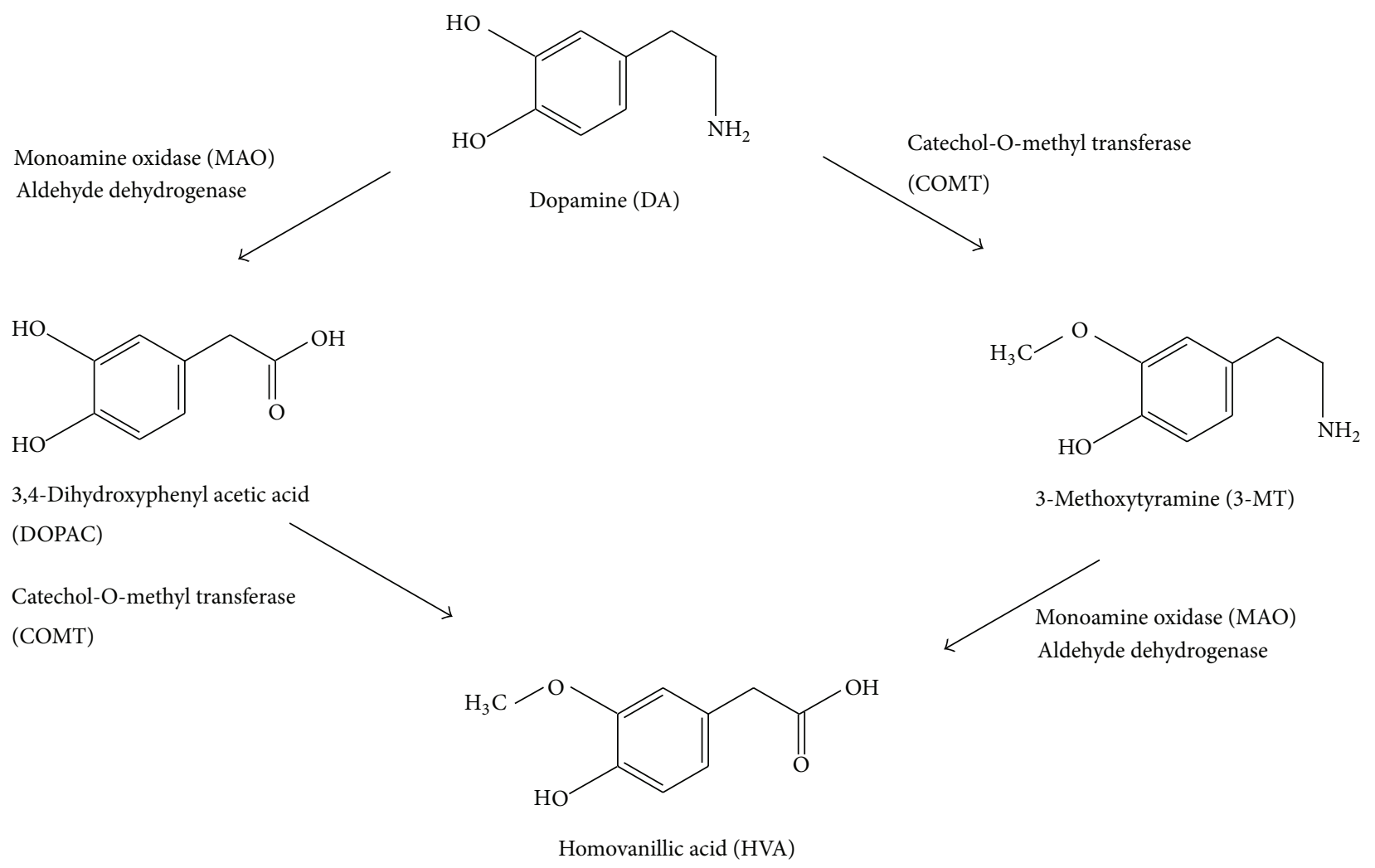

FIGURE 2: Dopamine metabolism.

membrane monoamine transporters. Once in the synaptic neuron, amphetamine exercises a reverse influence on the action of DA transporters (DAT) and forces DA molecules out of storage vesicles and into the synaptic gap [6]. The DA transporter is a sodium-coupled symporter protein responsible for modulating the concentration of extraneuronal DA in the brain [7]. The DA now in the cytosol is then repackaged into vesicles by the action of vesicular monoamine transport, $\mathrm{VMAT}_{2}[8]$.

\section{Metabolism of DA}

The enzymatic breakdown of DA to its inactive metabolites is carried out by catechol-O-methyl transferase (COMT) and monoamine oxidase (MAO) (Figure 2). This degradative action can be performed by the MAO isoforms MAO-A and MAO-B. It should be noted that COMT is predominantly expressed by glial cells. In neurons, this enzyme is either missing or found at very low levels. MAO-B is mainly found in astrocytes, whereas MAO-A predominates in catecholaminergic neurons like the cells of the SN. MAO breaks down dopamine to 3,4-dihydroxyphenylacetaldehyde (DOPAL), which in turn is degraded to form 3,4-dihydroxyphenylacetic acid (DOPAC) by the action of the enzyme aldehyde dehydrogenase (Figure 3) [9].

Another pathway for the metabolism of DA involves the enzyme COMT, which converts it to 3-methoxytyramine (3MT). Then, 3-MT is reduced by MAO to HVA and eliminated in the urine. As a result, the inhibition of monoamine oxidase has been considered as an adjunctive therapy in neurodegenerative disorders such as Alzheimer's and Parkinson's disease (PD) [10]. However, MAO inhibitors are used to increase DA levels and not to decrease hydrogen peroxide production. Actually, neurons have different antioxidant systems, for example, catalase and glutathione, to cope with $\mathrm{H}_{2} \mathrm{O}_{2}$ production. Furthermore, the MAO-derived DOPAC metabolite is probably much more toxic than $\mathrm{H}_{2} \mathrm{O}_{2}$. The inactivation of DA in the brain, striatum, and basal ganglia is mediated by reuptake via DAT followed by enzymatic action of MAO, which breaks it down to DOPAC. Nevertheless, there are few DATs in the frontal cortex, and this leads to the breakdown of DA via another pathway that involves the norepinephrine transporter (NET) on neighboring norepinephrine neurons, proceeded by the enzymatic action of COMT that breaks DA down to 3-MT [11], which may be a way to design therapies against neurological disorders. The velocity of DA degradation is usually faster in the DAT pathway than in NET. In mice, DA is degraded in the caudate nucleus via the DAT pathway within 200 milliseconds, in comparison with 2,000 milliseconds in the frontal cortex [11]. Nondegraded DA is repackaged by $\mathrm{VMAT}_{2}$ in the vesicles for reuse.

Dopaminergic neurons are found principally in the VTA of the midbrain, the substantia nigra pars compact, and the arcuate nucleus of hypothalamus. The axons of these neurons project to different areas of the brain through major pathways known as mesocortical, mesolimbic, and nigrostriatal pathways [12]. The mesolimbic pathway connects the VTA to the nucleus accumbens. The somata of the neurons 


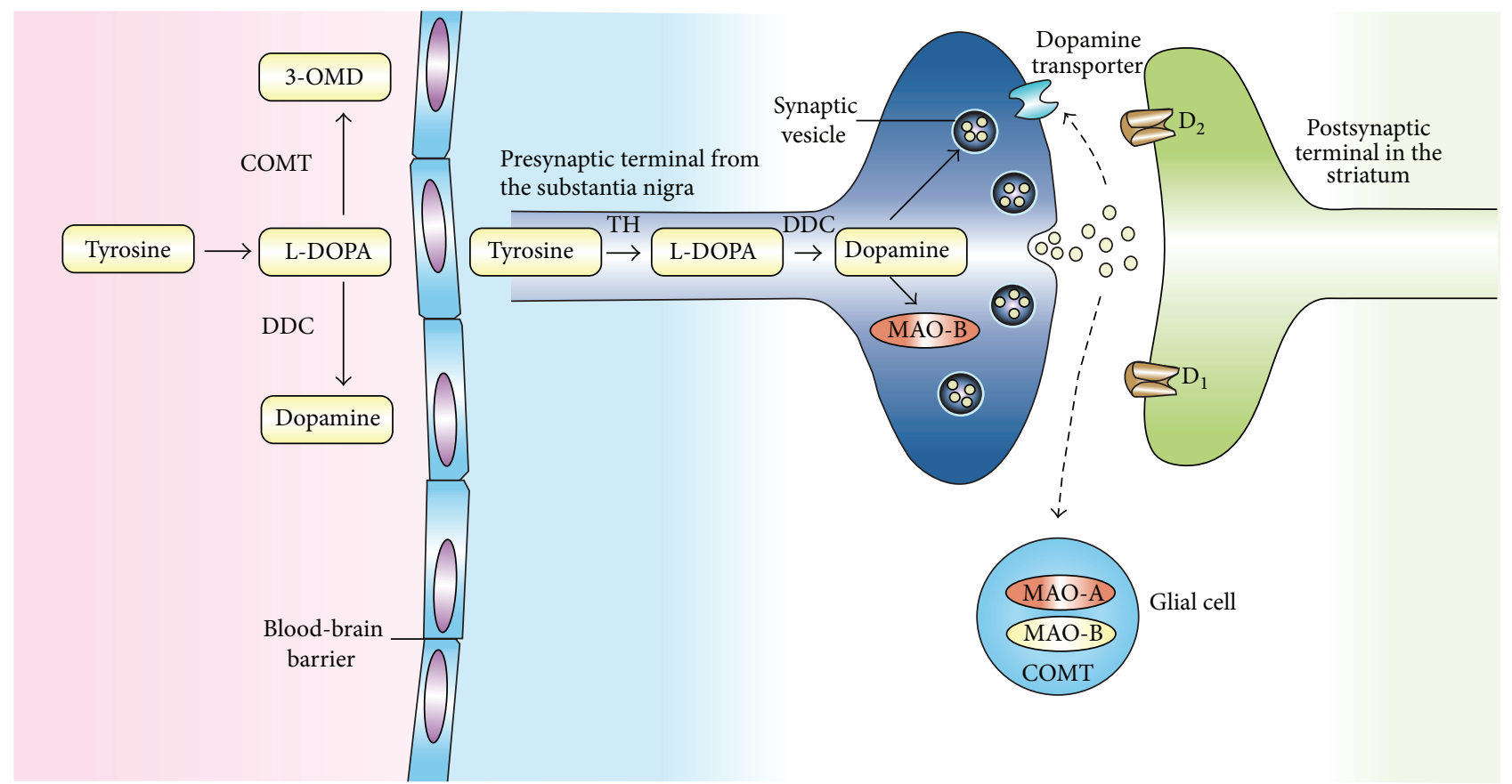

FIgURE 3: Dopamine metabolism pathways.

originate in the VTA, and, from there, DA is transported to the nucleus accumbens through the amygdala and the hippocampus. The nigrostriatal pathway joins the substantia nigra with the neostriatum. The neuronal somata are located in the substantia nigra, and the axons of these neurons are ramified into the caudate nucleus and putamen. This pathway is also connected to the basal ganglia motor loop. All of the innervations originating from these pathways explain many of the effects produced when the DA system is activated [13]. For instance, the VTA and the nucleus accumbens connected through the mesolimbic pathway are central to the brain reward system [14].

The modulation of extracellular DA levels occurs by two mechanisms, designated as tonic and phasic DA transmission. The former takes place when a small amount of DA is discharged independent of neuronal activity. This type of discharge is usually regulated by the activity of neurons and neurotransmitter reuptake [15]. The latter occurs when DA is released by the activity of DA-containing cells. Schultz et al. in a study carried out in monkeys reported that this activity is characterized by the irregular pacemaking activity of single spikes and rapid bursts of typically 2-6 spikes in quick succession [16], while Brozoski et al. affirmed that concentrated bursts of activity result in a greater increase of extracellular DA levels than would be expected from the same number of spikes distributed over a longer period of time [17], as a consequence of dopamine metabolism.

\section{The Reuptake}

DA reuptake can be inhibited by cocaine and amphetamines, but each has a different mechanism of action [18]. Cocaine is a DA transporter and norepinephrine transporter blocker. It inhibits the uptake of DA, which results in an increase in DA lifetime, thereby producing an overabundance. Disruptions in these mechanisms following chronic cocaine use contribute to addiction, due, in part, to the unique architecture of the mesocortical pathway. By blocking dopamine reuptake in the cortex, cocaine elevates dopamine signaling at extrasynaptic receptors, prolonging $\mathrm{D}_{1}$-receptor activation and the subsequent activation of intracellular signaling cascades, and thus induces long-lasting maladaptive plasticity [19]. Although Barr et al. have identified a novel mechanism by which cocaine promotes activation of $\mathrm{D}_{1}$-expressing $\mathrm{nAcc}$ neurons, the enhancement of inositol 1,4,5-trisphosphate receptors $\left(\mathrm{IP}_{3} \mathrm{R}\right)$ mediated responses via $\sigma_{1} \mathrm{R}$ activation at the endoplasmic reticulum, resulting in augmented $\mathrm{Ca}^{2+}$ release and amplified depolarization due to subsequent stimulation of transient receptor potential canonical channels (TRPC) [20].

\section{Role of Dopamine in Oxidative Stress}

It is well known that mitochondrial dysfunction and oxidative stress contribute in a significant way to the development of PD [21].

A loss of 5-10\% of dopaminergic neurons has been found in every decade of aging and an increase in brain oxidative damage is associated with age, and aging is considered a risk factor for $\mathrm{PD}$. The expansive nature of oxidative damage includes mitochondrial dysfunction, DA autooxidation, $\alpha$ synuclein aggregation, glial cell activation, alterations in calcium signaling, and excess-free iron. An increased incidence of PD may be correlated with alterations in the transcriptional activity of various pathways, including nuclear factor erythroid 2-related factor 2 , glycogen synthase kinase $3 \beta$, 
mitogen activated protein kinase, nuclear factor kappa B, and the reduced activity of superoxide dismutase, catalase, and glutathione with aging [22]. PD is a neurodegenerative disease that usually affects people older than 65 years [23].

Blast-wave-induced traumatic brain injury results in increased hypothalamic expression of oxidative stress markers and activation of the sympathoadrenal medullary axis, due to increased sympathetic excitation. This mechanism may involve elevated AT1 receptor expression and NADPH oxidase levels in the hypothalamus, which is related to DA [24].

The pathway to mitochondrial dysfunction begins with oxidative phosphorylation, which produces superoxide radicals, formed by one superoxide anion, one hydroxyl radical, and free radicals (FR) that come from organic compounds. Alcoxyl, peroxyl, hydrogen peroxide, and singlet oxygen [25], are byproducts that are deposited in the mitochondria, thereby making this organelle the main site for the generation of reactive oxygen species (ROS) within the cell and the first line of defense against oxidative stress [26]. However, superoxide also functions as a signaling molecule, different from signals mediated by hydrogen peroxide, hydroxyl radicals, or peroxynitrite. Although, a well-known role of superoxide is a precursor of reactive hydroxyl radicals by the superoxide-dependent Fenton reaction, the formation of peroxynitrite results in damage to target molecules and leads to pathological disorders, as was reported by Afanas'ev [27]. This author suggested that superoxide signaling depends on nucleophilic reactions. It is necessary to clarify that an oxidant is an element or compound in an oxidationreduction (redox) reaction that accepts an electron from another species. Due to the fact that it gains electrons, a superoxidant is often a molecule that contains many oxygen atoms and offers a high oxidant capacity.

Studies have suggested that mitochondrial c-Jun Nterminal kinase (JNK) plays a role in the etiology of 6-hydroxydopamine- (6-OHDA-) induced oxidative stress [28]. These authors suggest that 6-OHDA induced cell death through activating PI3K/Akt pathway and inhibiting JNK pathway. On this basis, it was suggested that inhibitors that block the association of JNKs within the mitochondria might be useful neuroprotective agents for the treatment of PD [27], and probably dysfunction in the projections of dopaminergic neurons of the nigrostriatal DA pathway from the substantia nigra to the dorsal striatum would slowly lead to PD [29].

Oxidative stress and hydrogen peroxide $\left(\mathrm{H}_{2} \mathrm{O}_{2}\right)$ have been implicated as the underlying factors in the initiation and progression of PD. Increases in endogenous $\mathrm{H}_{2} \mathrm{O}_{2}$ in the dorsal striatum attenuated electrically evoked DA release and also decreased basal DA levels [30]. The degeneration of the nigrostriatal pathway in PD is associated with oxidative stress and oxidized DA [31]. On the other hand, selenium transport protein (selenoprotein $\mathrm{P}$ ) and Seppl expressed by neurons of the substantia nigra of the midbrain indicate a role for Seppl in the nigrostriatal pathway, which suggests that local release of Seppl in the striatum may be important for signaling and/or synthesis of other selenoproteins with neuroprotective activity [32]. Selenoprotein P (Sepp1) and its receptor, apolipoprotein E receptor 2 (apoER2), account for brain retaining selenium better than other tissues, Sepp1apoER2 interactions supply selenium for maintenance of brain neurons, to protect the severe neurodegeneration and death in mild selenium deficiency [33].

Pharmacological inhibition of brain inflammation and endoplasmic reticulum stress prevented glucose intolerance due to $\mathrm{A} \beta$ oligomers ( $\mathrm{A} \beta \mathrm{Os}$ ), which act via a central route to affect peripheral glucose homeostasis [34]. A $\beta$ oligomers affect the hypothalamus and reveal a link between hypothalamic dysfunctions in metabolic disorders [35]. The consumption of $\beta$-phenethylamine- $(\beta$-PEA-) containing food for a long time is a neurological risk with many pathological consequences [36]. $\beta$-PEA toxicity is associated with hydroxyl radical (HO) production and oxidative stress generation in dopaminergic areas of the brain. $\beta$-PEA toxicity may be blocked by inhibition of mitochondrial complex-I [37].

PD has a multifactorial mechanism. Oxidative stress and neuroinflammation, including activation of NADPHdependent oxidases, play a major role in the progression of dopaminergic cell death [38]. A possible role for DNA repair systems in ageing and neurodegenerative diseases after DNA damage was observed in the brain of individuals affected by neurodegenerative diseases. A study of DNA repair gene polymorphisms (XRCC1 Arg399Gln, XRCC3 Thr241Met XPD Lys751Gln, XPG Asp1104His, APE1 Asp148Glu, and HOGG1 Ser326Cys) suggested that APE1, $\mathrm{XRCC1}$, and XRCC3 genetic variants might be a risk factor for $\mathrm{PD}$ by increasing oxidative stress, which might cause the loss of dopaminergic cells in the substantia nigra and locus coeruleus, which could in turn lead to abnormal signal transmission and the development of PD [39].

NADPH oxidase (NOX) was originally identified in immune cells, playing an important microbicidal role. In neurodegenerative and cerebrovascular diseases, inflammation is increasingly being recognized as contributing negatively to neurological outcome, with NADPH oxidase as an important source of superoxide. The activated enzyme complex transports electrons to oxygen, thus producing the superoxide anion $\left(\mathrm{O}_{2}{ }^{--}\right)$, a precursor of reactive oxygen species, and is the advantage of a targeted NADPH oxidase inhibitor that would inhibit the production of superoxide [40]. Indeed, Noxl/Racl could serve as a potential therapeutic target for PD because dopaminergic neurons are equipped with a Noxl/Racl superoxide-generating system; however, stress-induced Noxl/Racl activation causes oxidative DNA damage and neurodegeneration [41].

Another possible etiology of PD could be due to the loss of serum response factor (SRF), which leads to a decrease in the levels of antiapoptotic proteins, brain-derived neurotrophic factor (BDNF), and Bcl-2, all of which are considered to be a key cause of increased sensitivity to oxidative stress and dysfunction of the SRF-activating mitogen-associated kinase pathway [42]. Organs with a reduced capacity for regeneration like the brain are highly affected by inflammation, and neuroinflammation is recognized as a major contributor to epileptogenesis [43].

Peripheral inflammation provokes brain immune response involving microglial activation, elaboration of proinflammatory 
TABLE 1: Studies of drugs that alter levels of dopamine or its metabolites in clinical disorders. $\uparrow$ up, $\downarrow$ down.

\begin{tabular}{|c|c|c|c|}
\hline Drug & Clinical disorder & Dopamine or metabolites & Ref. \\
\hline Rasagiline & Antidepressant & MAO-A and MAO-B in the brain $\downarrow$ & [86] \\
\hline Methamphetamine (METH) & Addiction & $\begin{array}{l}\text { Expression of fosb, fral, and fra2 in } \\
\text { the nucleus accumbens (NAc) } \downarrow\end{array}$ & [87] \\
\hline Ladostigil & Antidepressant & MAO-A and MAO-B in the brain $\downarrow$ & {$[86]$} \\
\hline Risperidone/donepezil & Parkinsonian features & Dopamine transporter activity $\uparrow$ & {$[88]$} \\
\hline $\begin{array}{l}\text { Cocaine, heroin, or } \\
\text { methamphetamine }\end{array}$ & Addiction & Extracellular dopamine in CNS $\uparrow$ & [89] \\
\hline $\begin{array}{l}\text { 1-Methyl-4-phenyl-1,2,3,6- } \\
\text { tetrahydropyridine } \\
\text { (MPTP) }\end{array}$ & Parkinsonian features & Dopamine and $\mathrm{TH} \downarrow$ & {$[90]$} \\
\hline PAOPA & Schizophrenia & $\begin{array}{l}\text { Active site of the dopamine } \mathrm{D}(2) \\
\text { receptor } \downarrow\end{array}$ & {$[91]$} \\
\hline Methylphenidate & Cocaine addiction & Dopamine transporter $\downarrow$ & {$[92]$} \\
\hline Phenelzine & $\begin{array}{l}\text { Depression and anxiety } \\
\text { disorders }\end{array}$ & Dopamine levels in brain $\uparrow$ & {$[93]$} \\
\hline Amphetamine & $\begin{array}{l}\text { Attention deficit } \\
\text { hyperactivity disorder }\end{array}$ & Extracellular dopamine $\uparrow$ & [94] \\
\hline L-DOPA & Parkinson disease & Brain dopamine levels $\uparrow$ & {$[95]$} \\
\hline $\begin{array}{l}3,4- \\
\text { Methylenedioxymethamphetamine }\end{array}$ & Addiction & Brain dopamine levels $\uparrow$ & {$[96]$} \\
\hline $\begin{array}{l}\text { Flupenthixol, perphenazine, and } \\
\text { zotepine }\end{array}$ & Tauopathies & Dopamine $\mathrm{D}(2)$ receptor $\downarrow$ & {$[97]$} \\
\hline Asenapine & $\begin{array}{l}\text { Acute schizophrenia, manic } \\
\text { episodes, bipolar I disorder }\end{array}$ & Brain dopamine levels $\uparrow$ & {$[98]$} \\
\hline Pramipexole & Depression & Dopamine receptor $\mathrm{D}(3) \uparrow$ & [99] \\
\hline
\end{tabular}

cytokines, and reactive oxygen species. Thus, inflammation produces a secondary injury to neurons. A significant part of this response in the brain is mediated by cyclooxygenase (COX) and COX-2 through downstream proinflammatory prostaglandin (PG) signaling [44]. The anti-inflammatory effect of $\mathrm{COX}$ in the brain is mediated by $\mathrm{PGE}_{2} \mathrm{EP}_{4}$ signaling, and the findings of Shi et al. [45] identify the PGE(2) EP3 receptor as a novel proinflammatory, proamyloidogenic, and synaptotoxic signaling pathway. Furthermore, the authors suggest a role of COX-PGE(2) EP3 signaling in the development of AD. These data suggest that LPS induced proinflammatory gene expression in the hippocampus and isolated adult microglia is decreased by a $\mathrm{EP}_{4}$ selective agonist. $\mathrm{EP}_{4}$ agonists significantly reduced levels of proinflammatory cytokines and chemokines in plasma, indicating that the activation of peripheral $\mathrm{EP}_{4}$ gives protection to the brain against systemic inflammation. This suggests that an attractive strategy to prevent the onset and/or delay the progression of neurodegenerative diseases should address the mechanism that is directly implicated in controlling oxidative stress and the inflammatory response. This hypothesis is supported by the work of Kato et al., who proposed that microglial modulation may be a key target in the treatment of various psychiatric disorders [46].

The central nervous system and dopaminergic neurotransmission are associated with the development of addiction. This assertion is supported by the argument that drugs such as nicotine, cocaine, and amphetamine directly or indirectly increase the mesolimbic DA reward pathway and by the neurobiological theory that the DA pathway is pathologically altered in addicted persons [47]. Cocaine, nicotine, and amphetamine have both direct and downstream effects on dopaminergic systems. Cocaine affects the HPA axis and brain nuclei responsible for movements. Cocaine's rewarding effects are through its action on dopaminergic signaling pathways. Therefore, any therapeutic strategy for the abuse of these drugs should target the improvement of the efficacy and tolerability of DA transporters and other molecular targets (Table 1) in clinical disorders.

\section{The Endocrine System and Dopamine}

The depletion of DA may lead to upregulation of the reninangiotensin system (RAS) to compensate for DA depletion [48]. Nevertheless, hyperactivation of the RAS has many consequences, among which are the aggravation of NADPH oxidase activity and exacerbation of oxidative stress and the microglial inflammatory response and dopaminergic neuron loss [49].

DA is the primary neuroendocrine inhibitor of prolactin secretion by the anterior pituitary gland [50]. The pathway to this inhibitory action begins in the hypothalamic arcuate nucleus, whose neurons produce DA, which is emptied into hypothalamohypophyseal blood vessels of the median eminence, responsible for supplying blood to the anterior pituitary gland, the location of lactotrope cells. These cells 
TABLE 2: Neuroprotector and antioxidant effect of compounds that alter the dopaminergic metabolism.

\begin{tabular}{|c|c|c|c|}
\hline Substance & Effects & Tissue or animal models & Ref. \\
\hline Carnosic acid (CA) & $\begin{array}{l}\text { Protection against lipid peroxidation } \\
\text { and GSH reduction levels and } \\
\text { antiapoptotic and antioxidative action }\end{array}$ & $\begin{array}{l}\text { Human neuroblastoma } \\
\text { SH-SY5Y cells }\end{array}$ & [100] \\
\hline Hesperidin & $\begin{array}{l}\text { Reduction in glutathione peroxidase } \\
\text { and catalase activity, total reactive } \\
\text { antioxidant potential }\end{array}$ & Striatum mice & {$[101]$} \\
\hline Carnosic acid & $\begin{array}{l}\text { Prevent apoptosis through an increase } \\
\text { in glutathione S-transferase P (GSTP) } \\
\text { expression via activation of the } \\
\text { PI3K/Akt/NF- } \kappa \text { B pathway }\end{array}$ & $\begin{array}{l}\text { Human neuroblastoma } \\
\text { SH-SY5Y cells }\end{array}$ & {$[102]$} \\
\hline $\begin{array}{l}\text { Alkaloids from Piper longum } \\
\text { (PLA) }\end{array}$ & $\begin{array}{l}\text { Upregulate the activities of SOD, } \\
\text { GSH-Px, CAT, the content of GSH, } \\
\text { and the total antioxidant capacity and } \\
\text { decrease the content of NOS and the } \\
\text { content of MDA, NO }\end{array}$ & $\begin{array}{l}\text { Sustantia nigra and } \\
\text { striatum of rats }\end{array}$ & [103] \\
\hline $\begin{array}{l}\text { Novel (E)-3,4-dihydroxystyryl } \\
\text { aralkyl sulfones and sulfoxides }\end{array}$ & $\begin{array}{l}\text { Neuroprotective, antioxidative, and } \\
\text { antineuroinflammatory properties }\end{array}$ & Neuronal cells & {$[104]$} \\
\hline Fenofibrate & $\begin{array}{l}\text { Protected against decreased level of } \\
\text { DA and excessive production of } \\
\text { reactive oxygen species (ROS) }\end{array}$ & Rats & [105] \\
\hline $\begin{array}{l}\text { 2-[[(1,1- } \\
\text { Dimethylethyl)oxidoimino]- } \\
\text { methyl]-3,5,6-trimethylpyrazine } \\
\text { (TBN) }\end{array}$ & $\begin{array}{l}\text { Remarkable neurorescue effects to } \\
\text { increase the number of dopaminergic } \\
\text { neurons and reduce ROS }\end{array}$ & Mice and rats & {$[106]$} \\
\hline $\begin{array}{l}\text { D-440 is a novel highly selective } \\
D_{3} \text { agonist }\end{array}$ & $\begin{array}{l}\text { Neuroprotection in cell survival and } \\
\text { apoptosis }\end{array}$ & Dopaminergic MN9D cells & {$[107]$} \\
\hline Gallic acid & $\begin{array}{l}\text { Significantly increased passive } \\
\text { avoidance memory and total thiol and } \\
\text { GPx contents and also decreased MDA } \\
\text { levels }\end{array}$ & Nigral tissue & [108] \\
\hline Garcinia indica extract & $\begin{array}{l}\text { Acted as an effective neuroprotective } \\
\text { agent for striatal dopaminergic } \\
\text { neurons }\end{array}$ & Rat & [109] \\
\hline$( \pm)-\alpha$-Lipoic acid & Induced reversal of oxidative stress & $\begin{array}{c}\text { Human neuroblastoma } \\
\text { SH-SY5Y cells } \\
\end{array}$ & [110] \\
\hline
\end{tabular}

secrete prolactin continuously in the absence of DA. Thus, DA is sometimes referred to as the prolactin-inhibiting factor (PIF), prolactin-inhibiting hormone $(\mathrm{PIH})$, or prolactostatin [51].

Wang et al. discovered that $D_{1}$ and $D_{4}$ receptors are responsible for the cognitive-enhancing effects of DA, whereas $D_{2}$ receptors are more specific for motor actions [52]. In humans, antipsychotic drugs that have been found to reduce the activities of DA lead to impairments in concentration and reductions in motivation and inability to experience pleasure (anhedonia) [53]. The prolonged use of DA has been associated with tardive dyskinesia, an irreversible movement disorder [54]. Gonadal hormones are greatly affected by antipsychotic drugs. In women, these drugs are associated with low levels of estradiol and progesterone, while, in men, they significantly reduce the levels of testosterone and dehydroepiandrosterone (DHEA) [55].

The gynecological effects of antipsychotic drugs in women center on hyperprolactinemia, whose main consequences are amenorrhea, cessation of the normal ovarian cycle, loss of libido, occasional hirsutism, false positive pregnancy tests, and the long-term risk of osteoporosis [56]. In men, hyperprolactinemia produced by antipsychotics causes gynecomastia, lactation, impotence, loss of libido, and hypospermatogenesis [57]. Other effects of these drugs include weight gain, drooling, diabetes, sexual dysfunction, dysphoria (abnormal depression and discontent), fatigue, heart rhythm problems, stroke, and heart attack [56].

\section{Neuroprotective Substances That Alter Dopamine Metabolism}

Several studies have reported that antioxidants play an important role in Parkinson's disease [58], and the administration of antioxidant drugs might be used to prevent neuronal death produced by oxidative mechanisms in dopamine metabolism (Table 2). 


\section{Dopamine Metabolism and Antidepressants}

Many drugs with antidepressant and antipsychotic properties, including drugs of abuse and endogenous chemicals such as DA, are primarily metabolized in the liver by cytochrome P450 (CYPs) enzymes. Moreover, this degradation can also occur in extrahepatic organs and the brain. Knowledge of brain CYP-mediated metabolism may help in understanding why patients respond differently to drugs used in psychiatry and may predict the risk for psychiatric disorders, including neurodegenerative diseases and substance abuse [59].

Wood reported the role of opioid and cannabinoid transmission in the modulation of food palatability and pleasure of food consumption and noted that this pathway is independent of brain DA [60]. This may explain why food motivation in animals is independent of brain DA concentration. Nevertheless, other consummatory pleasures as feeling or motivating to a person may be more associated with DA.

The brain reward system is strongly associated with DA, which functions to provoke feelings of enjoyment and reinforcement, both of which motivate a person to perform certain works. The release of DA in areas such as the nucleus accumbens and the prefrontal cortex is principally due to rewarding experiences such as food, sex, drugs, and neutral stimuli that are associated with them [61]. Behavioral activation and effort-related processes are regulated by DA of the mesolimbic area, a critical component of brain circuitry.

The principal source of DA in the brain is the dopaminergic neurons of the midbrain. DA is involved in the control of movement and in error signals for reward prediction, motivation, and cognition [61].

Schizophrenia, autism, attention deficit hyperactivity disorders, and drug abuse are other pathological disorders that have been associated with DA dysfunction.

The firing of dopaminergic neurons has been hypothesized to be motivational as a consequence of reward anticipation. The basis of this hypothesis hinges on the fact that a greater reward than expected leads to an increase in the firing of dopaminergic neurons, which consequently increases desire or motivation towards the reward [61]. Nevertheless, recent findings have revealed that some dopaminergic neurons react in consonance with the expectations of reward neurons, while others seem to respond to unpredictability. Moreover, the same findings showed a predominance of reward neurons in the ventromedial region of the substantia nigra pars compact and in the ventral tegmental area. Neurons in these areas project mainly to the ventral striatum and thus might transmit value-related information in regard to reward values [62]. Nonreward neurons are predominant in the dorsolateral area of the substantia nigra pars compacta, which projects to the dorsal striatum and may relate to orienting behavior. Ideas on the role of DA in desire, motivation, and pleasure emanated from studies carried out in animals. In one such study, rats were subjected to depletion of the neostriatum by $99 \%$ using 6-hydroxydopamine and nucleus accumbens DA. Foraging behavior is modulated by DA through the activation of brain systems that register reward upon finding a food source [63]. Highly palatable food raises DA levels in monkey, but a prolonged presence of this palatable food makes DA levels decline [64].

DA in the mesolimbic pathway increases general arousal and goal directed behaviors and decreases latent inhibition. These effects augment the creative drive to generate ideas. Thus, creativity is a three-factor model in which the frontal lobes, the temporal lobes, and the mesolimbic DA system [65] play a part. Some authors suggest that the frontal cortex and striatum are more sensitive to oxidative burden, which could be related to the parallel monoamine perturbations [66].

\section{Consideration for Treatments}

Individuals suffering from schizophrenia display an increase in the activity of the dopaminergic system in the mesolimbic pathway. There is decreased activity in the mesocortical pathway. Therefore, these two pathways are blamed for the different sets of symptoms in schizophrenia.

Antipsychotic drugs act as DA antagonists [67]. Psychosis and schizophrenia produce highly abnormal dopaminergic transmission. Nevertheless, clinical studies associating schizophrenia with brain DA metabolism have produced controversial or negative results [68]. The levels of HVA in the cerebrospinal fluid are the same in schizophrenics and controls [69]. Antipsychotic drugs have an inhibitory effect on DA at the level of the receptors and block the neurochemical effects in a dose-dependent manner. Typical antipsychotics commonly act on $\mathrm{D}_{2}$ receptors while they atypically act on $\mathrm{D}_{2}$ and $\mathrm{D}_{1}, \mathrm{D}_{3}$ and $\mathrm{D}_{4}$ receptors, with a low affinity for DA receptors in general [70].

Levodopa is a DA precursor used in various forms to treat $\mathrm{PD}$ and dopa-responsive dystonia. Other inhibitors that can be coadministered with levodopa use an alternative metabolic route for producing DA involving catecholO-methyl transferase. However, oxidative stress and mitochondrial dysfunction can be produced by an increase in endogenous 6-OHDA [71].

As a theoretical possibility, an increase in endogenous 6-OHDA would trigger the formation of Lewy bodies in dopaminergic neurons and eventually lead to their degeneration. Such neurodegeneration could be attenuated using potent antioxidants together with L-DOPA. This would ultimately delay the progression of PD [72]. L-DOPA binds to GPE (Gly-Pro-Glu) by the N-terminal tripeptide of insulinlike growth factor-I. This bond is naturally cleaved in the plasma and brain. GPE has neuroprotective effects since it crosses the blood-CSF and the functional CSF-brain barriers and binds to glial cells, and this tripeptide might represent a promising strategy to supply L-DOPA to Parkinson's patients [73].

The effects of DA on immune cells depend on their physiological state. DA can activate resting T cells, but it can also inhibit them on being activated [74].

This chapter could provide a novel insight into our understanding of the biological mechanisms of neurological disorders and a potential explanation that showed perspectives associated with DA deficits in common clinical disorders that have remained in humans through evolution. 
9.1. Amphetamines to Treat DA Disorders. Amphetamine acts to increase DA concentration in the synaptic gap through a mechanism that is different from that of cocaine. The structures of amphetamine and methamphetamine are similar to those of DA [75].

Both have two pathways of entrance into the presynaptic terminal bouton, direct diffusion through the neuronal membrane or uptake via DA transporters [76]. The main target of many drugs, such as psychostimulants, nootropics, antidepressants, and some recreational drugs including cocaine, is the DAT. Some stimulants increase the concentration of DA in the presynaptic cleft, an increase that gives rise to an excitatory effect when these drugs are consumed [77].

By increasing the action of the direct pathway in the basal ganglia, DA reduces the effect of the indirect pathway. Macchi et al. found that insufficient DA biosynthesis in dopaminergic neurons causes PD, a condition in which one loses the ability to execute smooth, controlled movements [78].

In addition to the above functions, DA also plays an important role in the neurocognitive function of the frontal lobe by controlling the flow of information from the brain. Hence, DA disorders in this region of the brain can cause a decline in neurocognitive functions, especially in memory, attention, and problem-solving. Moreover, decreased concentrations of DA in the prefrontal cortex are thought to contribute to attention deficit disorder [79].

\section{Expert Commentary}

Disorders such as schizophrenia and PD are associated with altered immune function and changes in brain DA receptors and DA signaling pathways. L-DOPA, DA agonists, inhibitors of DA metabolism, or brain grafts with cells expressing a high level of $\mathrm{TH}$ are possible treatment methods for PD because of their ability to correct or bypass an enzymatic deficiency that is the key characteristic of this disease. Another promising target in PD treatment is PPAR- $\gamma$, which is a key regulator of the immune response. Treatment can also be achieved using agonists with the potential to impact pro- and anti-inflammatory cytokine expression in immune cells at the transcriptional level [80]. Intrastriatal expression of DA synthesizing enzymes could be a promising approach to gene therapy. Expression could be achieved using adenoassociated virus vectors/marrow stromal cells (MSCs) or nonviral intravenous agents involving rat transferrin receptor monoclonal antibodies (TfRmAb) targeted to PE glycated immunoliposomes. The detention or removal of nitrating agents may protect against protein inactivation and limit neuronal injury in PD, thus suggesting the necessity of developing therapeutic agents capable of doing this without interfering with normal neuronal function [81].

The emergence of a highly interesting new area of nonpharmacological treatment of TH dysfunction has occurred in the past few years. TH normalization could provide neuroprotection in PD patients. These new approaches focus on the use of dietetic therapy or the active constituents of plants and phytomedicines, which are believed to provide protection for people suffering from PD [82].

Zhang et al. found that the activation of Akt, a serine/threonine kinase that promotes cell survival and growth, increases the ability of neurons to survive after injury and regenerates lost neuronal connections [83]. These authors suggest that Akt-signaling pathway disinhibition could provide a valuable strategy to enhance survival, function, and integration of grafted DA neurons within the host striatum and improve survival and integration of different forms of neural grafts.

\section{Five-Year View}

In the last few years, the identification of the relationship between immune and neurodegenerative diseases has been demonstrated based on the effect of monoclonal antibodies. Several antibodies that recognize linear $\mathrm{A} \beta$ segments also react with fibrils formed from unrelated amyloid sequences. This suggests that reactivity with linear segments of $\mathrm{A} \beta$ does not mean that the antibody is sequence specific [84].

In fact, clinical trials on PD have shown that transplants of embryonic mesencephalic DA neurons form new functional connections within the host striatum, but the therapeutic benefits have been highly variable. One obstacle has been poor survival and integration of grafted DA neurons [85].

This mini review indicates that novel therapies may offer significant improvements and target new mechanisms of neurological disorders. These novel therapeutic strategies involve drugs that act not only on the targets of the dopamine transporter but also on other molecular targets to improve drug efficacy and tolerability and obtain the needed improvements in protein homeostasis to alter the metabolism of DA. We recommend that further studies be carried out in different animal and human models.

\section{Key Points}

(i) Dysfunction of dopamine pathways has been implicated in development of Parkinsonism.

(ii) Common biochemical markers of dopamine are used to monitor its effect and its role in disorders.

\section{Conflict of Interests}

The authors declare that there is no conflict of interests regarding the publication of this paper.

\section{Acknowledgment}

The final version was revised and edited by Taylor and Francis Editing Services.

\section{References}

[1] T. R. Slaney, O. S. Mabrouk, K. A. Porter-Stransky, B. J. Aragona, and R. T. Kennedy, "Chemical gradients within brain extracellular space measured using low flow push-pull perfusion sampling in vivo," ACS Chemical Neuroscience, vol. 4, no. 2, pp. 321-329, 2013.

[2] P. Calabresi, B. Picconi, A. Tozzi, and M. Di Filippo, "Dopamine-mediated regulation of corticostriatal synaptic plasticity," Trends in Neurosciences, vol. 30, no. 5, pp. 211-219, 2007. 
[3] J. H. An, B.-K. Oh, and J. W. Choi, "Detection of tyrosine hydroxylase in dopaminergic neuron cell using gold nanoparticles-based barcode DNA," Journal of Biomedical Nanotechnology, vol. 9, no. 4, pp. 639-643, 2013.

[4] C. Tolleson and D. Claassen, "The function of tyrosine hydroxylase in the normal and Parkinsonian brain," CNS and Neurological Disorders-Drug Targets, vol. 11, no. 4, pp. 381-386, 2012.

[5] T. Müller, "Catechol-o-methyltransferase inhibitors in Parkinson's disease," Drugs, vol. 75, pp. 157-174, 2015.

[6] S. C. Steffensen, K. D. Bradley, D. M. Hansen et al., "The role of connexin-36 gap junctions in alcohol intoxication and consumption," Synapse, vol. 65, no. 8, pp. 695-707, 2011.

[7] K. C. Schmitt, R. B. Rothman, and M. E. Reith, "Nonclassical pharmacology of the dopamine transporter: atypical inhibitors, allosteric modulators, and partial substrates," Journal of Pharmacology and Experimental Therapeutics, vol. 346, no. 1, pp. 210, 2013.

[8] S. Chen, X. J. Zhang, W. J. Xie, H. Y. Qiu, H. Liu, and W. D. Le, "A new VMAT-2 inhibitor NBI-641449 in the treatment of huntington disease," CNS Neuroscience \& Therapeutics, vol. 21, no. 8, pp. 662-671, 2015.

[9] S. J. López-Pérez, A. Morales-Villagrán, and L. Medina-Ceja, "Effect of perinatal asphyxia and carbamazepine treatment on cortical dopamine and DOPAC levels," Journal of Biomedical Science, vol. 22, article 14, 2015.

[10] D. D. Mousseau and G. B. Baker, "Recent developments in the regulation of monoamine oxidase form and function: is the current model restricting our understanding of the breadth of contribution of monoamine oxidase to brain dysfunction?" Current Topics in Medicinal Chemistry, vol. 12, no. 20, pp. 21632176, 2012.

[11] A. A. Grace and B. S. Bunney, "The control of firing pattern in nigral dopamine neurons: single spike firing," The Journal of Neuroscience, vol. 4, no. 11, pp. 2866-2876, 1984.

[12] A. A. Prasad and R. J. Pasterkamp, "Axon guidance in the dopamine system," Advances in Experimental Medicine and Biology, vol. 651, pp. 91-100, 2009.

[13] B. P. Cho, D. Y. Song, S. Sugama et al., "Pathological dynamics of activated microglia following medial forebrain bundle transection," Glia, vol. 53, no. 1, pp. 92-102, 2006.

[14] A. Y. Deutch and R. H. Roth, "The determinants of stressinduced activation of the prefrontal cortical dopamine system," Progress in Brain Research, vol. 85, pp. 367-403, 1990.

[15] M. S. Szczypka, M. A. Rainey, D. S. Kim et al., "Feeding behavior in dopamine-deficient mice," Proceedings of the National Academy of Sciences of the United States of America, vol. 96, no. 21, pp. 12138-12143, 1999.

[16] W. Schultz, P. Apicella, and T. Ljungberg, "Responses of monkey dopamine neurons to reward and conditioned stimuli during successive steps of learning a delayed response task," Journal of Neuroscience, vol. 13, no. 3, pp. 900-913, 1993.

[17] T. J. Brozoski, R. M. Brown, H. E. Rosvold, and P. S. Goldman, "Cognitive deficit caused by regional depletion of dopamine in prefrontal cortex of rhesus monkey," Science, vol. 205, no. 4409, pp. 929-932, 1979.

[18] M. H. Cheng, E. Block, F. Hu, M. C. Cobanoglu, A. Sorkin, and I. Bahar, "Insights into the modulation of dopamine transporter function by amphetamine, orphenadrine, and cocaine binding," Frontiers in Neurology, vol. 6, article 134, 2015.

[19] W. C. Buchta and A. C. Riegel, "Chronic cocaine disrupts mesocortical learning mechanisms," Brain Research, 2015.
[20] J. L. Barr, E. Deliu, G. C. Brailoiu et al., "Mechanisms of activation of nucleus accumbens neurons by cocaine via sigma-1 receptor-inositol 1,4,5-trisphosphate-transient receptor potential canonical channel pathways," Cell Calcium, vol. 58, no. 2, pp. 196-207, 2015.

[21] H. Liu, P. Mao, J. Wang, T. Wang, and C. Xie, "Allicin protects PC12 cells against 6-OHDA-induced oxidative stress and mitochondrial dysfunction via regulating mitochondrial dynamics," Cellular Physiology and Biochemistry, vol. 36, no. 3, pp. 966-979, 2015.

[22] H. Kumar, H.-W. Lim, S. V. More et al., "The role of free radicals in the aging brain and Parkinson's disease: convergence and parallelism," International Journal of Molecular Sciences, vol. 13, no. 8, pp. 10478-10504, 2012.

[23] E. Siegl, B. Lassen, and S. Saxer, "Incontinence, a common issue for people with Parkinson's disease. A systematic literature review," Pflege Zeitschrift, vol. 66, no. 9, pp. 540-544, 2013.

[24] N. Tümer, S. Svetlov, M. Whidden et al., "Overpressure blast-wave induced brain injury elevates oxidative stress in the hypothalamus and catecholamine biosynthesis in the rat adrenal medulla," Neuroscience Letters, vol. 544, pp. 62-67, 2013.

[25] B. Halliwell and J. M. C. Gutteridge, "Oxygen toxicity, oxygen radical, transition metals and disease," Biochemical Journal, vol. 219, no. 1, pp. 1-14, 1984.

[26] M. Reale, M. Pesce, M. Priyadarshini, M. A. Kamal, and A. Patruno, "Mitochondria as an easy target to oxidative stress events in Parkinson's disease," CNS and Neurological Disorders-Drug Targets, vol. 11, no. 4, pp. 430-438, 2012.

[27] I. B. Afanas'ev, "On mechanism of superoxide signaling under physiological and pathophysiological conditions," Medical Hypotheses, vol. 64, no. 1, pp. 127-129, 2005.

[28] X.-H. Han, M.-N. Cheng, L. Chen et al., "7,8-Dihydroxyflavone protects PC12 cells against 6-hydroxydopamine-induced cell death through modulating PI3K/Akt and JNK pathways," Neuroscience Letters, vol. 581, pp. 85-88, 2014.

[29] I. Mocchetti, A. Bachis, R. L. Nosheny, and G. Tanda, "Brainderived neurotrophic factor expression in the substantia nigra does not change after lesions of dopaminergic neurons," Neurotoxicity Research, vol. 12, no. 2, pp. 135-143, 2007.

[30] M. Spanos, J. Gras-Najjar, J. M. Letchworth, A. L. Sanford, J. V. Toups, and L. A. Sombers, "Quantitation of hydrogen peroxide fluctuations and their modulation of dopamine dynamics in the rat dorsal striatum using fast-scan cyclic voltammetry," ACS Chemical Neuroscience, vol. 4, no. 5, pp. 782-789, 2013.

[31] M. Inden, Y. Kitamura, K. Takahashi et al., "Protection against dopaminergic neurodegeneration in Parkinson's disease-model animals by a modulator of the oxidized form of DJ-1, a wildtype of familial Parkinson's disease-linked PARK7," Journal of Pharmacological Sciences, vol. 117, no. 3, pp. 189-203, 2011.

[32] F. P. Bellinger, A. V. Raman, R. H. Rueli et al., "Changes in selenoprotein $\mathrm{P}$ in substantia nigra and putamen in Parkinson's disease," Journal of Parkinson's Disease, vol. 2, no. 2, pp. 115-126, 2012.

[33] R. F. Burk, K. E. Hill, A. K. Motley et al., "Selenoprotein P and apolipoprotein e receptor-2 interact at the blood-brain barrier and also within the brain to maintain an essential selenium pool that protects against neurodegeneration," The FASEB Journal, vol. 28, no. 8, pp. 3579-3588, 2014.

[34] H. M. Rivera, K. J. Christiansen, and E. L. Sullivan, "The role of maternal obesity in the risk of neuropsychiatric disorders," Frontiers in Neuroscience, vol. 9, article 194, 2015. 
[35] J. R. Clarke, N. M. Lyra e Silva, C. P. Figueiredo et al., "Alzheimer-associated $\mathrm{A} \beta$ oligomers impact the central nervous system to induce peripheral metabolic deregulation," EMBO Molecular Medicine, vol. 7, no. 2, pp. 190-210, 2015.

[36] D. Bouglé and S. Bouhallab, "Dietary bioactive peptides: human studies," Critical Reviews in Food Science and Nutrition, 2015.

[37] A. Borah, R. Paul, M. K. Mazumder, and N. Bhattacharjee, "Contribution of $\beta$-phenethylamine, a component of chocolate and wine, to dopaminergic neurodegeneration: implications for the pathogenesis of Parkinson's disease," Neuroscience Bulletin, vol. 29, no. 5, pp. 655-660, 2013.

[38] J. L. Labandeira-Garcia, J. Rodriguez-Pallares, A. I. RodríguezPerez, P. Garrido-Gil, B. Villar-Cheda, and R. Valenzuela, "Brain angiotensin and dopaminergic degeneration: relevance to Parkinson's disease," American Journal of Neurodegenerative Disease, vol. 1, pp. 226-244, 2012.

[39] M. Gencer, S. Dasdemir, B. Cakmakoglu et al., "DNA repair genes in Parkinson's disease," Genetic Testing and Molecular Biomarkers, vol. 16, no. 6, pp. 504-507, 2012.

[40] B. Cairns, J. Y. Kim, X. N. Tang, and M. A. Yenari, "NOX inhibitors as a therapeutic strategy for stroke and neurodegenerative disease," Current Drug Targets, vol. 13, no. 2, pp. 199-206, 2012.

[41] D.-H. Choi, A. C. Cristóvão, S. Guhathakurta et al., "NADPH oxidase 1-mediated oxidative stress leads to dopamine neuron death in Parkinson's disease," Antioxidants and Redox Signaling, vol. 16, no. 10, pp. 1033-1045, 2012.

[42] C. Rieker, A. Schober, A. Bilbao, G. Schütz, and J. R. Parkitna, "Ablation of serum response factor in dopaminergic neurons exacerbates susceptibility towards MPTP-induced oxidative stress," European Journal of Neuroscience, vol. 35, no. 5, pp. 735741, 2012.

[43] J. A. Gorter, E. A. van Vliet, and E. Aronica, "Status epilepticus, blood-brain barrier disruption, inflammation, and epileptogenesis," Epilepsy \& Behavior, vol. 49, pp. 13-16, 2015.

[44] J. Shi, J. Johansson, N. S. Woodling, Q. Wang, T. J. Montine, and K. Andreasson, "The prostaglandin E2 E-prostanoid 4 receptor exerts anti-inflammatory effects in brain innate immunity," The Journal of Immunology, vol. 184, no. 12, pp. 7207-7218, 2010.

[45] J. Shi, Q. Wang, J. U. Johansson et al., "Inflammatory prostaglandin $\mathrm{E}_{2}$ signaling in a mouse model of Alzheimer disease," Annals of Neurology, vol. 72, no. 5, pp. 788-798, 2012.

[46] T. A. Kato, Y. Yamauchi, H. Horikawa et al., "Neurotransmitters, psychotropic drugs and microglia: clinical implications for psychiatry," Current Medicinal Chemistry, vol. 20, no. 3, pp. 331344, 2013.

[47] M. A. Patriquin, I. E. Bauer, J. C. Soares, D. P. Graham, and D. A. Nielsen, "Addiction pharmacogenetics: a systematic review of the genetic variation of the dopaminergic system," Psychiatric Genetics, vol. 25, no. 5, pp. 181-193, 2015.

[48] H. Nakaoka, M. Mogi, H. Kan-no et al., "Angiotensin II type 2 receptor signaling affects dopamine levels in the brain and prevents binge eating disorder," Journal of the Renin-AngiotensinAldosterone System, 2015.

[49] J. L. Labandeira-Garcia, J. Rodriguez-Pallares, B. Villar-Cheda, A. I. Rodríguez-Perez, P. Garrido-Gil, and M. J. Guerra, "Aging, angiotensin system and dopaminergic degeneration in the substantia nigra," Aging and Disease, vol. 2, no. 3, pp. 257-274, 2011.

[50] S. Vijayraghavan, M. Wang, S. G. Birnbaum, G. V. Williams, and A. F. T. Arnsten, "Inverted-U dopamine D1 receptor actions on prefrontal neurons engaged in working memory," Nature Neuroscience, vol. 10, no. 3, pp. 376-384, 2007.

[51] M. Medic-Stojanoska, T. Icin, I. Pletikosic et al., "Risk factors for accelerated atherosclerosis in young women with hyperprolactinemia," Medical Hypotheses, vol. 84, no. 4, pp. 321-326, 2015.

[52] M. Wang, S. Vijayraghavan, and P. S. Goidman-Rakic, "Selective D2 receptor actions on the functional circuitry of working memory," Science, vol. 303, no. 5659, pp. 853-856, 2004.

[53] S. Scheggi, T. Pelliccia, A. Ferrari, M. de Montis, and C. Gambarana, "Impramine, fluoxetine and clozapine differently affected reactivity to positive and negative stimuli in a model of motivational anhedonia in rats," Neuroscience, vol. 291, pp. 189202, 2015.

[54] J. Wu, H. Xiao, H. Sun, L. Zou, and L.-Q. Zhu, "Role of dopamine receptors in ADHD: a systematic meta-analysis," Molecular Neurobiology, vol. 45, no. 3, pp. 605-620, 2012.

[55] M. F. Reynolds-May, H. A. Kenna, W. Marsh et al., "Evaluation of reproductive function in women treated for bipolar disorder compared to healthy controls," Bipolar Disorders, vol. 16, no. 1, pp. 37-47, 2014.

[56] J. Peuskens, L. Pani, J. Detraux, and M. de Hert, "The effects of novel and newly approved antipsychotics on serum prolactin levels: a comprehensive review," CNS Drugs, vol. 28, no. 5, pp. 421-453, 2014.

[57] C. W. Berridge and D. M. Devilbiss, "Psychostimulants as cognitive enhancers: the prefrontal cortex, catecholamines, and attention-deficit/hyperactivity disorder," Biological Psychiatry, vol. 69, no. 12, pp. e101-el11, 2011.

[58] G. Scapagnini, S. Davinelli, F. Drago, A. De Lorenzo, and G. Oriani, "Antioxidants as antidepressants: fact or fiction?" CNS Drugs, vol. 26, no. 6, pp. 477-490, 2012.

[59] S. Miksys and R. F. Tyndale, "Cytochrome P450-mediated drug metabolism in the brain," Journal of Psychiatry and Neuroscience, vol. 38, no. 3, pp. 152-163, 2013.

[60] P. B. Wood, "Role of central dopamine in pain and analgesia," Expert Review of Neurotherapeutics, vol. 8, no. 5, pp. 781-797, 2008.

[61] J. W. Maas, C. L. Bowden, A. L. Miller et al., "Schizophrenia, psychosis, and cerebral spinal fluid homovanillic acid concentrations," Schizophrenia Bulletin, vol. 23, no. 1, pp. 147-154, 1997.

[62] J. A. Lieberman, J. M. Kane, and J. Alvir, "Provocative tests with psychostimulant drugs in schizophrenia," Psychopharmacology, vol. 91, no. 4, pp. 415-433, 1987.

[63] W. M. Abi-Saab, "The NMDA antagonist model for schizophrenia: promise and pitfalls," Pharmacopsychiatry, vol. 31, no. 2, pp. 104-109, 1998.

[64] V. J. Galani and D. G. Rana, "Depression and antidepressants with dopamine hypothesis-a review," International Journal of Pharmaceutical Frontier Research, vol. 1, pp. 45-60, 2011.

[65] W. Birkmayer, W. Linauer, and D. Storung, "Tyrosin and tryptophan-metabolisms in depression patients," Archiv für Psychiatrie und Nervenkrankheiten, vol. 213, pp. 377-387, 1970.

[66] A. Ahmad, N. Rasheed, G. M. Ashraf et al., "Brain region specific monoamine and oxidative changes during restraint stress," Canadian Journal of Neurological Sciences, vol. 39, no. 3, pp. 311-318, 2012.

[67] A. Newman-Tancredi and M. S. Kleven, "Comparative pharmacology of antipsychotics possessing combined dopamine D2 and serotonin 5-HT 1A receptor properties," Psychopharmacology, vol. 216, no. 4, pp. 451-473, 2011. 
[68] Y. Yamaguchi, Y. A. Lee, and Y. Goto, "Dopamine in socioecological and evolutionary perspectives: implications for psychiatric disorders," Frontiers in Neuroscience, vol. 9, article 219, 2015.

[69] P. Beldade and P. M. Brakefield, "The genetics and evo-devo of butterfly wing patterns," Nature Reviews Genetics, vol. 3, no. 6, pp. 442-452, 2002.

[70] M. Lambert, B. G. Schimmelmann, A. Karow, and D. Naber, "Subjective well-being and initial dysphoric reaction under antipsychotic drugs-concepts, measurement and clinical relevance," Pharmacopsychiatry, vol. 36, supplement 3, pp. 181-190, 2003.

[71] Y.-H. Jung, D.-H. Kang, M. S. Byun et al., "Influence of brainderived neurotrophic factor and catechol $O$-methyl transferase polymorphisms on effects of meditation on plasma catecholamines and stress," Stress, vol. 15, no. 1, pp. 97-104, 2012.

[72] A. Borah and K. P. Mohanakumar, "L-DOPA inducedendogenous 6-hydroxydopamine is the cause of aggravated dopaminergic neurodegeneration in Parkinson's disease patients," Medical Hypotheses, vol. 79, no. 2, pp. 271-273, 2012.

[73] A. Minelli, C. Conte, I. Cacciatore, C. Cornacchia, and F. Pinnen, "Molecular mechanism underlying the cerebral effect of Gly-Pro-Glu tripeptide bound to L-dopa in a Parkinson's animal model," Amino Acids, vol. 43, no. 3, pp. 1359-1367, 2012.

[74] T. B. Ferreira, P. O. Barros, B. Teixeira et al., "Dopamine favors expansion of glucocorticoid-resistant IL-17-producing T cells in multiple sclerosis," Brain, Behavior, and Immunity, vol. 41, pp. 182-190, 2014.

[75] M. J. Ferris, E. S. Calipari, J. H. Rose et al., "A single amphetamine infusion reverses deficits in dopamine nerve-terminal function caused by a history of cocaine self-administration," Neuropsychopharmacology, 2015.

[76] V. M. Chiu and J. O. Schenk, "Mechanism of action of methamphetamine within the catecholamine and serotonin areas of the central nervous system," Current Drug Abuse Reviews, vol. 5, no. 3, pp. 227-242, 2012.

[77] K. Satoh and R. Nonaka, "In vitro screening of psychoactive drugs to prevent the abuses," Yakugaku Zasshi, vol. 128, no. 12, pp. 1771-1782, 2008.

[78] B. Macchi, R. Paola, F. Marino-Merlo, M. Felice, S. Cuzzocrea, and A. Mastino, "Inflammatory and cell death pathways in brain and peripheral blood in parkinson's disease," CNS \& Neurological Disorders_Drug Targets, vol. 14, no. 3, pp. 313-324, 2015.

[79] J. Huang, Z. Zhong, M. Wang et al., "Circadian modulation of dopamine levels and dopaminergic neuron development contributes to attention deficiency and hyperactive behavior," Journal of Neuroscience, vol. 35, no. 6, pp. 2572-2587, 2015.

[80] S. Tabrez, N. R. Jabir, S. Shakil et al., "A synopsis on the role of tyrosine hydroxylase in Parkinson's disease," CNS and Neurological Disorders_Drug Targets, vol.11, no. 4, pp. 395-409, 2012.

[81] C. Henze, C. Earl, J. Sautter et al., "Reactive oxidative and nitrogen species in the nigrostriatal system following striatal 6hydroxydopamine lesion in rats," Brain Research, vol. 1052, no. 1, pp. 97-104, 2005.

[82] S.-M. Liu, X.-Z. Li, Y. Huo, and F. Lu, "Protective effect of extract of Acanthopanax senticosus harms on dopaminergic neurons in Parkinson's disease mice," Phytomedicine, vol. 19, no. 7, pp. 631638, 2012.

[83] Y. Zhang, A.-C. Granholm, K. Huh et al., "PTEN deletion enhances survival, neurite outgrowth and function of dopamine neuron grafts to MitoPark mice," Brain, vol. 135, no. 9, pp. 27362749, 2012.

[84] A. Hatami, R. Albay, S. Monjazeb, S. Milton, and C. Glabe, "Monoclonal antibodies against $\mathrm{A} \beta 42$ fibrils distinguish multiple aggregation state polymorphisms in vitro and in Alzheimer disease brain," The Journal of Biological Chemistry, vol. 289, no. 46, pp. 32131-32143, 2014.

[85] B. Ghosh, C. Zhang, and G. M. Smith, "Bridging between transplantation therapy and neurotrophic factors in Parkinson's disease," Frontiers in Bioscience-Elite, vol. 6, no. 2, pp. 225-235, 2014.

[86] M. B. Youdim, "Multi target neuroprotective and neurorestorative anti-Parkinson and anti-Alzheimer drugs ladostigil and m30 derived from rasagiline," Experimental Neurobiology, vol. 22, no. 1, pp. 1-10, 2013.

[87] F. Saint-Preux, L. R. Bores, I. Tulloch et al., "Chronic coadministration of nicotine and methamphetamine causes differential expression of immediate early genes in the dorsal striatum and nucleus accumbens of Rats," Neuroscience, vol. 243, pp. 89-96, 2013.

[88] S. H. Kang and D.-K. Kim, "Drug induced parkinsonism caused by the concurrent use of donepezil and risperidone in a patient with traumatic brain injuries," Annals of Rehabilitation Medicine, vol. 37, no. 1, pp. 147-150, 2013.

[89] P. J. Gaskill, T. M. Calderon, J. S. Coley, and J. W. Berman, "Drug induced increases in CNS dopamine alter monocyte, macrophage and T cell functions: implications for HAND," Journal of Neuroimmune Pharmacology, vol. 8, no. 3, pp. 621642, 2013.

[90] K.-S. Lee, J.-K. Lee, H.-G. Kim, and H. R. Kim, "Differential effects of 1-methyl-4-phenyl-1,2,3,6-tetrahydropyridine on motor behavior and dopamine levels at brain regions in three different mouse strains," Korean Journal of Physiology and Pharmacology, vol. 17, no. 1, pp. 89-97, 2013.

[91] M. L. Tan, D. Basu, J. M. Kwiecien, R. L. Johnson, and R. K. Mishra, "Preclinical pharmacokinetic and toxicological evaluation of MIF-1 peptidomimetic, PAOPA: examining the pharmacology of a selective dopamine D2 receptor allosteric modulator for the treatment of schizophrenia," Peptides, vol. 42, pp. 89-96, 2013.

[92] E. C. Berglund, M. A. Makos, J. D. Keighron, N. Phan, M. L. Heien, and A. G. Ewing, "Oral administration of methylphenidate blocks the effect of cocaine on uptake at the Drosophila dopamine transporter," ACS Chemical Neuroscience, vol. 4, no. 4, pp. 566-574, 2013.

[93] D. Matveychuk, E. Nunes, N. Ullah, C. A. Velázquez-Martinez, E. M. MacKenzie, and G. B. Baker, "Comparison of phenelzine and geometric isomers of its active metabolite, $\beta$-phenylethylidenehydrazine, on rat brain levels of amino acids, biogenic amine neurotransmitters and methylamine," Journal of Neural Transmission, vol. 120, no. 6, pp. 987-996, 2013.

[94] D. P. Daberkow, H. D. Brown, K. D. Bunner et al., "Amphetamine paradoxically augments exocytotic dopamine release and phasic dopamine signals," The Journal of Neuroscience, vol. 33, no. 2, pp. 452-463, 2013.

[95] L. Szyrwiel, J. S. Pap, W. Malinka, Z. Szewczuk, A. Kotynia, and J. Brasun, "Interactions of anti-Parkinson drug benserazide with $\mathrm{Zn}(\mathrm{II}), \mathrm{Cu}(\mathrm{II}), \mathrm{Fe}(\mathrm{II})$ ions," Journal of Pharmaceutical and Biomedical Analysis, vol. 76, pp. 36-43, 2013.

[96] L. Hondebrink, S. Tan, E. Hermans, R. G. D. M. van Kleef, J. Meulenbelt, and R. H. S. Westerink, "Additive inhibition of human $\alpha 1 \beta 2 \gamma 2$ GABAA receptors by mixtures of commonly 
used drugs of abuse," NeuroToxicology, vol. 35, no. 1, pp. 23-29, 2013.

[97] A. V. McCormick, J. M. Wheeler, C. R. Guthrie, N. F. Liachko, and B. C. Kraemer, "Dopamine D2 receptor antagonism suppresses tau aggregation and neurotoxicity," Biological Psychiatry, vol. 73, no. 5, pp. 464-471, 2013.

[98] F. I. Tarazi and J. C. Neill, “The preclinical profile of asenapine: clinical relevance for the treatment of schizophrenia and bipolar mania," Expert Opinion on Drug Discovery, vol. 8, no. 1, pp. 93103, 2013.

[99] N. Tokunaga, M. E. Choudhury, N. Nishikawa et al., "Pramipexole upregulates dopamine receptor $\mathrm{D}_{2}$ and $\mathrm{D}_{3}$ expression in rat striatum," Journal of Pharmacological Sciences, vol. 120, no. 2, pp. 133-137, 2012.

[100] C.-R. Wu, C.-W. Tsai, S.-W. Chang, C.-Y. Lin, L.-C. Huang, and C.-W. Tsai, "Carnosic acid protects against 6-hydroxydopamine-induced neurotoxicity in in vivo and in vitro model of Parkinson's disease: involvement of antioxidative enzymes induction," Chemico-Biological Interactions, vol. 225, pp. 40-46, 2015.

[101] M. S. Antunes, A. T. R. Goes, S. P. Boeira, M. Prigol, and C. R. Jesse, "Protective effect of hesperidin in a model of Parkinson's disease induced by 6-hydroxydopamine in aged mice," Nutrition, vol. 30, no. 11-12, pp. 1415-1422, 2014.

[102] C.-Y. Lin, J.-H. Chen, R.-H. Fu, and C.-W. Tsai, "Induction of Pi form of glutathione $\mathrm{S}$-transferase by carnosic acid is mediated through PI3K/Akt/NF- $\kappa$ B pathway and protects against neurotoxicity," Chemical Research in Toxicology, vol. 27, no. 11, pp. 1958-1966, 2014.

[103] L. Zheng, H. Wang, Y.-Y. Ba et al., "Protective effect of alkaloids from Piper longum in rat dopaminergic neuron injury of 6-OHDA-induced Parkinson's disease," Zhongguo Zhongyao Zazhi, vol. 39, no. 9, pp. 1660-1665, 2014.

[104] X. Ning, Y. Guo, X. Wang et al., "Design, synthesis, and biological evaluation of (e)-3,4-dihydroxystyryl aralkyl sulfones and sulfoxides as novel multifunctional neuroprotective agents," Journal of Medicinal Chemistry, vol. 57, no. 10, pp. 4302-4312, 2014.

[105] J. K. Barbiero, R. Santiago, F. S. Tonin et al., "PPAR- $\alpha$ agonist fenofibrate protects against the damaging effects of MPTP in a rat model of Parkinson's disease," Progress in NeuroPsychopharmacology and Biological Psychiatry, vol. 53, pp. 3544, 2014.

[106] B. Guo, D. Xu, H. Duan et al., "Therapeutic effects of multifunctional tetramethylpyrazine nitrone on models of Parkinson's disease in vitro and in vivo," Biological and Pharmaceutical Bulletin, vol. 37, no. 2, pp. 274-285, 2014.

[107] S. Santra, L. Xu, M. Shah, M. Johnson, and A. Dutta, "D-512 and D-440 as novel multifunctional dopamine agonists: characterization of neuroprotection properties and evaluation of in vivo efficacy in a Parkinson's disease animal model," ACS Chemical Neuroscience, vol. 4, no. 10, pp. 1382-1392, 2013.

[108] M. T. Mansouri, Y. Farbood, M. J. Sameri, A. Sarkaki, B. Naghizadeh, and M. Rafeirad, "Neuroprotective effects of oral gallic acid against oxidative stress induced by 6-hydroxydopamine in rats," Food Chemistry, vol. 138, no. 2-3, pp. 1028-1033, 2013.

[109] B. V. Antala, M. S. Patel, S. V. Bhuva, S. Gupta, S. Rabadiya, and M. Lahkar, "Protective effect of methanolic extract of Garcinia indica fruits in 6-OHDA rat model of Parkinson's disease," Indian Journal of Pharmacology, vol. 44, no. 6, pp. 683-687, 2012.
[110] J. Deslauriers, C. Desmarais, P. Sarret, and S. Grignon, “ $\alpha$-Lipoic acid interaction with dopamine D2 receptor-dependent activation of the Akt/GSK-3 $\beta$ signaling pathway induced by antipsychotics: potential relevance for the treatment of schizophrenia," Journal of Molecular Neuroscience, vol. 50, no. 1, pp. 134-145, 2013. 


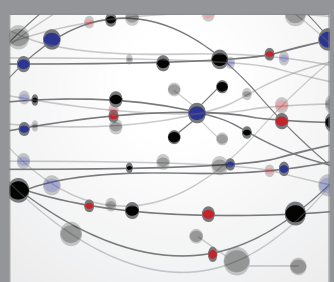

The Scientific World Journal
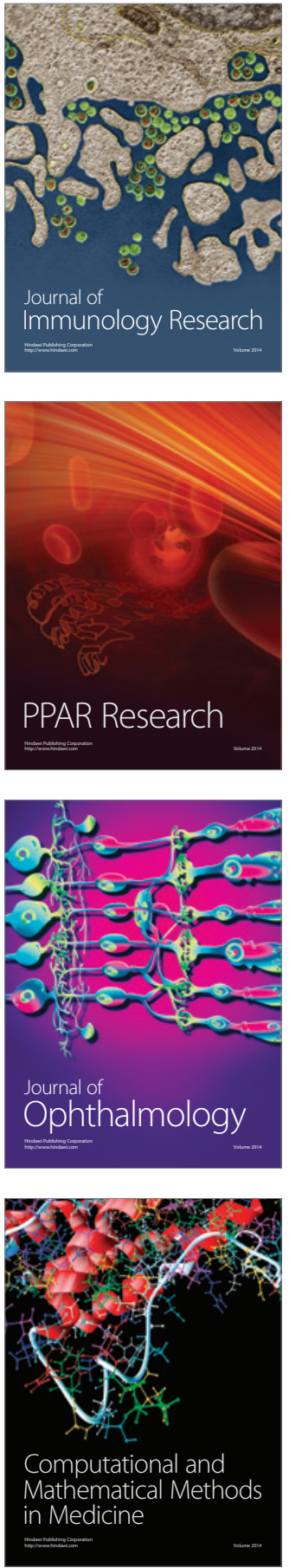

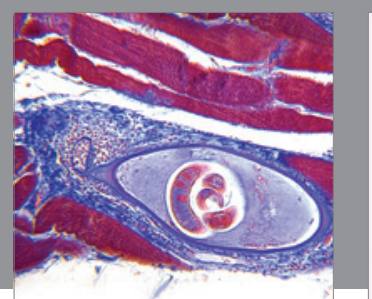

Gastroenterology Research and Practice

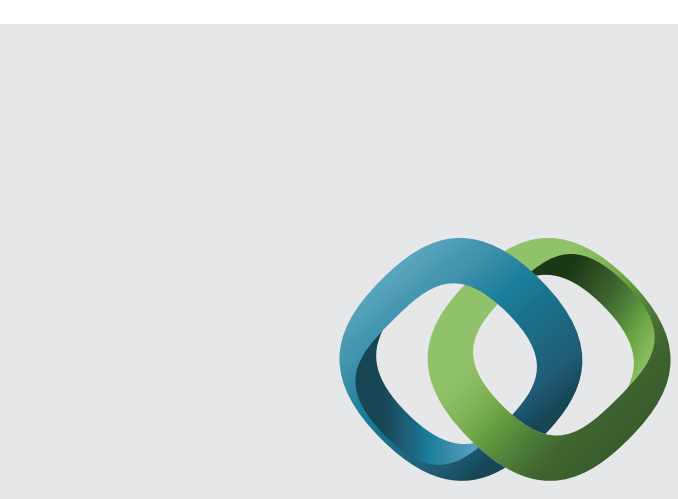

\section{Hindawi}

Submit your manuscripts at

http://www.hindawi.com
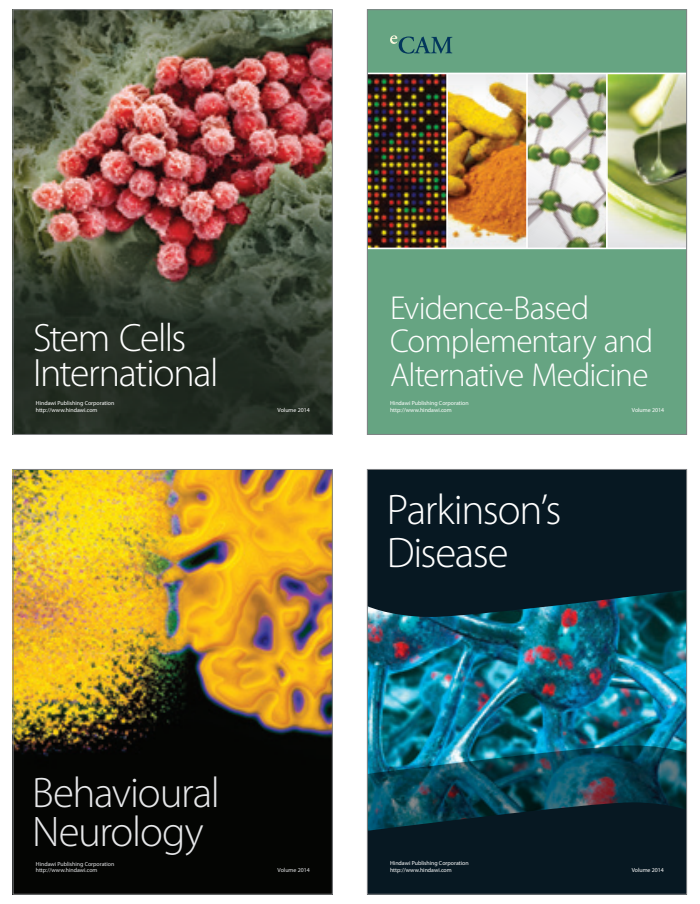
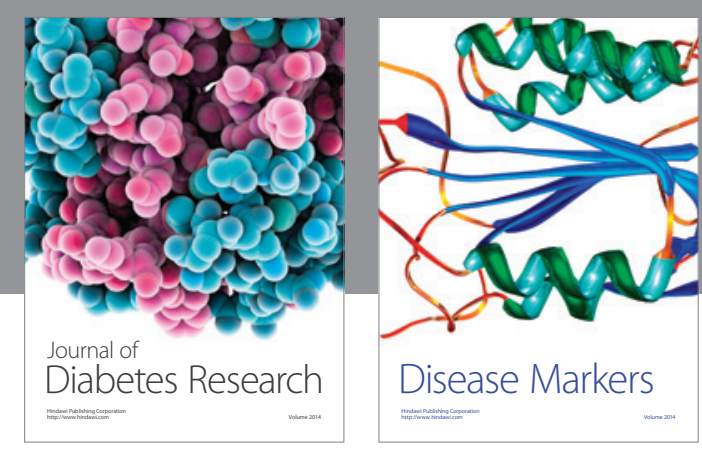

Disease Markers
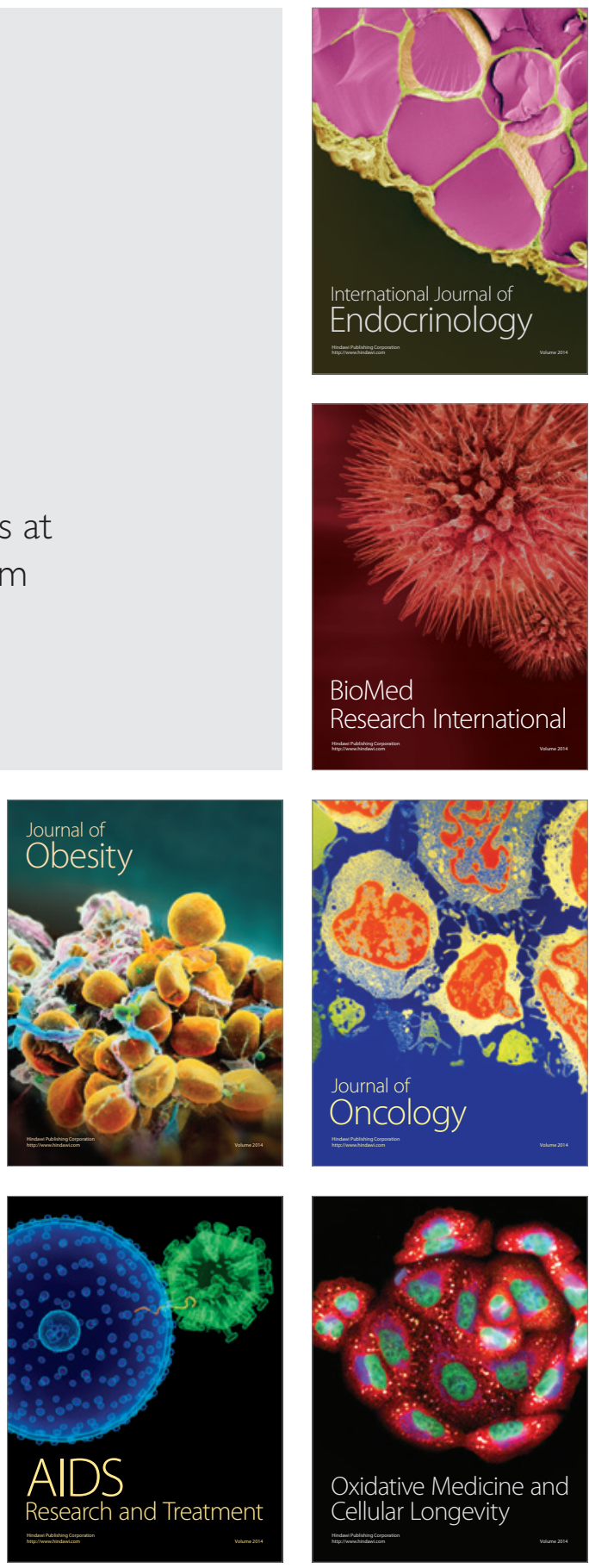